\title{
A BARBÁRIE DA REFLEXÃO E A DECADÊNCIA MORAL: A CRÍTICA DE VICO À CULTURA DO ILUMINISMO
}

H umberto A parecido de O liveira Guido U niversidade Federal de U berlândia guido@ufu.br

RESU M O : Este artigo apresenta o projeto de G. Vico para o estabelecimento da ciência moral. Vico esteve empenhado na emancipação do estudo das manifestações objetivas do espírito por intermédio da reforma do racionalismo cartesiano. A crítica ao iluminismo é feita com a retomada do conceito de barbárie no âmbito da filosofia, contrapondo-o ao conceito de esclarecimento do Século das Luzes.

Palavras-chave: G. Vico, racionalismo, esclarecimento.

Durante os últimos vinte anos de sua vida, Vico esteve empenhado no aprimoramento da sua obra magna, a Scienza nuova. $\mathrm{N}$ ão foram apenas correções e esclarecimentos, mas também notáveis modificações do estilo do texto. A expressão definitiva mereceu da crítica literária os seguintes adjetivos: obscura, fragmentada e repetitiva. 0 que pode parecer aos olhos alheios uma deficiência foi para Vico a coerência. Ele quis que a forma da sua obra oferecesse ao leitor as ásperas dificuldades para a compreensão do pensamento primitivo; lendo, o leitor experimenta com o próprio pensamento a maneira como os primeiros homens pensaram. Somente um especialista na língua latina seria capaz de conseguir tamanho efeito: 0 de retroceder a escrita até atingir a forma mais arcaica da expressão do pensamento bárbaro.

Os longos anos de erudição serviram para que Vico descobrisse a gênese do pensamento humano, isso porque 0 autor da Scienza nuova ${ }^{1}$ evitou o pedantismo dos doutos que buscam no passado a sua própria sabedoria do presente, transportando erroneamente para as origens do mundo um saber que não se situa no tempo remoto das experiências primordiais. Sob esse aspecto 
do estudo do passado, é oportuno registrar a proximidade entre a posição de Vico e a de Pedro Nava, um dos maiores memorialistas brasileiros do século passado. Em uma de suas últimas entrevistas, Pedro Nava referiu-se assim ao conhecimento do passado:

A memória não existe em estado puro: os fatos passados, quando evocados, arrastam consigo uma experiência sucessiva tão grande que já não são mais os mesmos. Por isso suas memórias têm muito de ficção, não no sentido da deformação da real idade, mas do seu en riquecimento, forçado pela maneira cumulativa como trabalha a memória. ${ }^{2}$

0 profundo conhecimento do passado e das suas tradições religiosas, culturais, políticas, sociais - não serve para a reprodução indefinida do presente ou para a adivinhação do futuro. 0 estudo da cultura permite o conhecimento do estado de geração das coisas, dando ao presente a historicidade que permite alimentar a convicção de que o futuro existirá, mas tal futuro é aquilo que os homens fazem por si mesmos. A experiência do passado é entendida por Vico como o patrimônio da memória, algo que sofre seguidas tran sformações, alteran do os significados originais e acrescentan do conteúdos novos. Somente a linguagem pode escavar a memória coletiva até atingir os primeiros sedimentos dos tempos primitivos. Essa busca obstinada da consciência mítica fez com que o velho professor de Retórica da U niversidade de N ápoles abrisse mão do seu refinamento de latinista e de douto da língua italiana, para servir-se da linguagem vulgar muito arcaica que ainda era ouvida nas ruas estreitas da sua cidade natal.

A língua é o maior patrimônio do passado, é a fonte privilegiada para a investigação dos tempos obscuros, quando tudo aquilo que éhumano tem a sua origem. Esseéo primeiro juízo encontrado na Sn44: "as origens da humanidade, foram por natureza, pequenas, rudes e extremamente obscuras" (Sn44, § 123).

A nova ciência que é anunciada no título da obra não é identificada facilmente. A esse respeito, Benedetto Croce (1980) 
entendeu que Vico não fez referência a uma ciência particular, portanto, a obra foi consagrada ao estabelecimento de uma ciência generalizante, capaz de abarcar o vasto domínio do mundo social. A observação de C roce é pertinente; após percorrer o texto da Sn44 fica em aberto qual seja a ciência que Vico reputa ser a sua contribuição para os estudos humanos. C ertamente, a Sn44 é um projeto de pesquisa voltado para a investigação da verdade nos domínios da cultura.

N as primeiras páginas da Sn44 Vico afirma que a sua obra introduz uma nova arte crítica para a pesquisa da verdade sobre os fundadores das nações. Não há ciência sem método - este é 0 consenso entre os modernos, Vico esteve atento ao preceito formulado por Descartes. A nova arte crítica tem função metodológica, pois o seu procedimento exige a associação da postura científica com a atitude filosófica. Ainda nos procedimentos, a arte crítica adentra os domínios da filologia e da filosofia, de modo que o saber resultante da aplicação do método é a síntese de ambas, acarretando a efetivação da filologia como ciência, isto é, promovendo o estudo das coisas humanas à esfera científica, o lugar do qual as disciplinas humanistas haviam sido desal ojadas e postas para fora do espectro da ciência pela mentalidade cientificista do século XVII. Para Vico, as disciplinas humanistas fundamentam uma espécie de fil osofia da autoridade, ou seja, o conhecimento da gênese do pensamento bárbaro, peculiar aos primeiros homens, que com as suas fábulas criaram o mundo civil. A novidade do procedimento metodológico é justificada pela inovação dos estudos mitológicos:

Porque, graças a outros princípios de mitologia aqui descobertos, seguidos de outros princípios da poesia aqui alcançados, se demonstra as fábulas terem sido verdadeiras e severas histórias dos costumes das antiqüíssimas gentes da G récia e, primeiramente, que as dos deuses foram as histórias dos tempos em que os homens da mais rude humanidade gentílica acreditaram que todas as coisas necessárias ou úteis ao gênero humano eram divindades, de cuja poesia foram autores os 
primeiros povos, que se descobrem terem sido todos de poetas teólogos, os quais, sem dúvida, nos narraram terem fundado as nações gentias com as fábulas dos deuses. $(S n 44, \S 7)$

A mitologia é composta pelas fábulas dos deuses e dos heróis; ambas são o mais fiel relato do mundo bárbaro, de modo que todas as pesquisas sobre as origens do mundo devem buscar na mitologia o material necessário para a elucidação da verdade sobre os primeiros homens eas suas instituições. A mitologia não guarda em seu interior uma filosofia oculta, somente a filosofia não está contida na consciência mítica, mas todas as outras ciências e artes responsáveis pela humanização do mundo encontram seus germes na consciência ingênua dos primeiros homens. A filosofia só foi possível no estágio subseqüente à primeira barbárie, no momento em que as primeiras comunidades humanas já se en contravam agrupadas nas primeiras cidades. D essa constatação deriva uma afirmação: a sabedoria poética é anterior à sabedoria dos filósofos; é, portanto, a sabedoria dos antigos que oferece os fundamentos para a elaboração filosófica da teoria do direito natural. $\mathrm{Na}$ Sn25, ${ }^{3}$ Vico esteve mais empenhado em criticar os principais representantes do jusnaturalismo. Seu argumento recai sobre as conjecturas dos teóricos do direito natural, que na maioria das vezes não foram capazes de enxergar o homem natural no seu estado natural. Para se referir a esse momento remoto, os jusnatural istas serviram-se de hipóteses que são plausíveis para a sociedade civil já constituída, mas que não servem para explicar as origens dessa sociedade de homens ferinos.

A barbárie é o ponto de partida para os estudos jurídicos. A abordagem dos tempos bárbaros tem como primeira dificuldade a imprecisão dos relatos; a segunda consiste nos equívocos de interpretação das fontes antigas. 0 antídoto para esses erros é muito simples e bem conhecido dos filósofos desde os primórdios da filosofia, trata-se da suspensão de juízo - a epoché dos céticos antigos. N esse caso, Vico exorta o leitor a abandonar, durante a pesquisa, a sua erudição e a sua condição de civilizado, para descer até a mente 
aturdida dos primeiros homens - os primeiros fundadores das nações - , "todos de robustíssimos sentidos e vastíssimas fantasias" $(\mathrm{Sn} 44, \S 6)$.

A fonte primária da pesquisa social é H omero, mas, tal como afirmou Sócrates no Í on, ${ }^{4}$ não basta conhecer os versos de $\mathrm{H}$ omero, é preciso ser 0 intérprete do seu pensamento. Sua interpretação poética oferece ao pesquisador o relato histórico da barbárie primitiva e a formação dos primeiros organismos sociais. O s poemas homéricos e as narrativas similares são as únicas possibilidades para se chegar o mais perto possível dos primeiros homens, aqueles que realmente existiram, que tiveram uma existência histórica. Vico não compartilhava das teorias modernas que alardeavam a imagem do homem natural servindo-se da figura do bom selvagem. Essas teorias não possuíam suporte filosófico, elas derivavam dos relatos dos viajantes que descreviam os traços e o comportamento dos habitantes das novas terras en contradas pelos navegantes europeus.

Vico não se opôs aos relatos dos viajantes; muito pelo contrário, ele próprio se serviu dessa literatura para confirmar os seus achados mitológicos (Sn44, § 337). Do mesmo modo que a interpretação da poesia antiga era deficiente, também a recepção das notícias advindas do N ovo M undo também era recebida com equívocos. Tais equívocos atestam que tanto os inovadores quanto os conservadores se en ganam quando 0 assunto é o direito natural. O s conservadores se apresentam como os fiéis intérpretes da sabedoria dos antigos, porém o que fazem é transportar para 0 passado os conhecimentos filosóficos do seu tempo, anulando por completo o modo de vida natural característico das comunidades primitivas. 0 sinovadores, isto é, os natural istas do Século das Luzes, tomam o relato da vida natural dos homens do $\mathrm{N}$ ovo M undo como a descrição do comportamento de indivíduos isolados, destituídos de laços sociais, e, com esses relatos, transferem suas conviç̧ões sobre o que deveria ser o caráter do homem para o comportamento dos habitantes primitivos das novas terras. 
A presunção de vários jusnaturalistas deixava $V$ ico insatisfeito, porque a característica marcante desses doutos era a ausência de realismo. 0 direito natural é um dos campos do conhecimento que mereceu atenção no projeto racionalista de Vico para as ciências humanas, tanto que ele assinalou essa matéria com o subtítulo da obra: sobre a natureza comum das nações. Q uando da publicação da Sn25, Vico recebeu uma crítica muito desfavorável, publicada em uma revista literária de Leipzig. Em sua resposta $V$ ico fez a defesa do propósito de sua obra, ${ }^{5}$ afirmando que da natureza comum das nações "deriva e resulta um conhecimento completo e uniforme das coisas humanas e divinas de todos os povos, do qual resulta um novo sistema de direito natural que é o principal corolário de tal Ciência" (Vici Vin., p. 346).

A matéria do direito natural começa quando o homem abandona o estado ferino para buscar abrigo e proteção; isso provoca de imediato o estabelecimento do primeiro laço social, que vem a ser a primeira forma de matrimônio, no qual a aliança decorre da insatisfação inconsciente da vida solitária. Portanto, onde os jusnaturalistas e contratualistas viam um homem natural em estado de natureza, Vico identifica um homem solitário em um estado ferino. A diferença substancial é que o homem solitário está fora da sociedade humana, viveu um período sem história, do qual não há registro. 0 nascimento da sociedade humana somente foi possível no momento em que o homem primitivo abandona o estado ferino.

Pode ser que 0 estado ferino seja o equivalente ao estado de natureza dos contratualistas, porém Vico foi enfático ao negar a existência da sociedade humana em um estado de completa ignorância, no qual sequer uma aliança precária entre um homem e uma mulher fosse plausível, dado o estado de guerra de todos contra todos. D essa primeira distinção entre $V$ ico e o pensamento do Século das Luzes fica evidente que as bases do direito natural não estão sob os pés de indivíduos isolados, pois somente quando os homens estabelecem laços - mesmo que muito precários - éque têm início os tempos históricos. 
Para Vico, a fala e a escrita nasceram juntas, o tempo histórico começou com uma língua muda, cujos caracteres foram os sinais naturais e as próprias coisas naturais. Em seguida, os homens das nações gentias falaram a língua heróica, tendo as insígnias eas armas nobres por caracteres. M esmo não dominando a escrita alfabética foi possível o registro histórico por intermédio das narrativas poéticas dos tempos divinos e heróicos, as quais permaneceram e foram, mais tarde, fixadas pela linguagem coloquial e pela escrita alfabética. A tese de Vico sobre os tempos históricos e a escrita da história é bem mais ousada do que aquela de $\mathrm{H}$ egel, que admite na história apenas os povos capazes de representar a sua história sob a forma narrativa. ${ }^{6}$

Retornando à questão do direito natural, eleé para Vico uma elaboração que atesta a existência da razão como força inata e é responsável pelo amadurecimento constante, identificado em sucessivas transformações, que resultaram no estabelecimento da sociedade civil. 0 direito natural não é sinônimo de direito individual, uma vez que o indivíduo isolado éinfelize insatisfeito, estando impossibilitado de entender o direito e a liberdade, pois a sua existência éoprimida pela ausência de laços sociais. 0 direito natural é peculiar à natureza comum dos homens, independente do tempo e do lugar. N atureza comum porque a racionalidade e a sociabilidade estão presentes em todos homens e os levam a viver em sociedade.

Mas o que move o homem solitário na direção da realização da sua verdadeira natureza? 0 que impulsiona o homem é a força inata que produz um primeiro pensamento que o distingue dos outros animais; é ainda um pensamento muito simples, contudo capaz de livrá-lo da solidão. Vico definiu essa primeira ação da mente humana com um pensamento espantoso de alguma divindade, cujo temor conteve a violência ferina e domesticou os seus impulsos naturais. Portanto, o direito natural começou com alguma cognição de Deus, da qual nunca os homens estiveram privados, mesmo quando eram selvagens, ferinos e imanes ( $\mathrm{Sn} 44$, § 339). 
0 primeiro pensamento é uma experiência individual, mas é sentido por todo o gênero humano, de modo que o pesquisador das coisas humanas pode experimentar com a sua razão a veracidade da tese de Vico sobre o primeiro pensamento, tão distante do horizonte moderno, no qual surge a pesquisa sobre o direito natural como norma da conduta dos primei ros homens; sobre a possibilidade do recurso à razão para a confirmação do achado mitológico das primeiras divindades, Vico afirmou que,

para alcançar a direção de tal primeiro pensamento humano nascido no mundo da gentilidade, encontramos as ásperas dificuldades que nos custaram a pesquisa de bem vinte anos, e [devemos] descer destas nossas naturezas humanas civilizadas até aquelas de fato ferinas e imanes, sobre as quais nos é, de fato, negado imaginar esomentea duras penas nosé permitido entender. (Sn44, § 338)

A mentalidade muito simples dos primeiros homens, de acordo com Vico, não era capaz de assimilar o primeiro pensamento como algo seu; do estranhamento entre a mente de quem produziu o pensamento e este surgiram as religiões bárbaras e com elas teve início o processo de antropomorfização da natureza. As religiões primitivas surgiram no momento em que as primeiras alianças foram celebradas quase que espontaneamente; somado a esses princípios surgiu, algum tempo depois, o sepultamento dos mortos, que atesta a crença inata na imortalidade da alma.

Esses três princípios - o pensamento espantoso de alguma divindade superior aos homens, os matrimônios e o sepultamento dos mortos - serviram para a consolidação do estado de família, um estágio preparatório na formação da sociedade civil. D a mesma forma que o estado ferino não é próprio da sociedade civil, também o estado de família ainda não se constitui como a forma plena da vida em sociedade, pois o mundo civil requer a associação de um número maior de indivíduos cujos vínculos não sejam tão-somente os laços sangüíneos. Mas a família, primeiro de filhos, depois, e 
propriamente, de filhos e de fâmulos se constitui na primeira forma de vida social.

A má interpretação das narrativas poéticas fizeram com que os eruditos das coisas antigas se en ganassem a respeito das formas de governo, a ponto de admitirem a monarquia como o primeiro regime político do mundo civil. Para Vico, os monarcas dos tempos obscuros nada mais eram que os primeiros pais de família cujo poder se estendia sobre os filhos e os fâmulos, não havendo no estado das famílias nada além do império privado dessas primeiras autoridades paternas. N esse primeiro estágio social prevaleceram as diferenças sociais, estando as potestades paternas acima de todos os outros membros da família; em seguida vinham os filhos que estavam totalmente submetidos à autoridade paterna, que tinha o pátrio poder sobre esses seus filhos.

U m pouco mais complexa era a relação entre a potestade paterna e os fâmulos, pois, no estado das famílias, estes ainda não eram os escravos, que somente surgi riam com as cidades eas guerras. O s fâmulos foram os primeiros servos do mundo humano, recorriam à proteção dos primeiros pais de família e, sem nenhuma idéia abstrata de contrato, se submetiam a essa autoridade e, em troca da vida, passavam a servir esses pais, tornando-se seus sócios. No estado das famílias prevaleceu a tolerância entre os membros da comunidade, mas as desigualdades foram evidentes, de modo que não tem fundamento a crença na igualdade natural entre os homens primitivos. A igualdade é algo construído historicamente e se consolida somente nos governos tipicamente humanos que chegam muitos séculos depois da formação dos primeiros governos civis.

0 estado das famílias correspondeu à idade dos deuses, um período extremamente dilatado da história universal durante o qual surgiram as primeiras criações humanas: as religiões e as famílias, harmoniosamente integradas umas às outras, pois as religiões eram consagradas às divindades dessas famílias, configurando-se em um culto doméstico. A administração do direito consistia na adivinhação dosauspícios ou sinais enviados por essas divindades aos homens. A 
idade dos deuses foi, porém, um período pel o qual passaram todos os povos primitivos, poistodos relatam a existência de uma divindade superior que os criou: Zeus para os gregos, Júpiter para os latinos, Javé para os hebreus.

No momento em que as famílias se tornaram numerosas e mais numerosos ainda os fâmulos, a autoridade paterna passou a ser insuportável para tentar manter estes últimos sob o poder das potestades paternas. No momento em que nem mesmo a força dos pais de família era suficiente para conter a revolta dos fâmulos surgiu, naturalmente, a união dessas potestades paternas, originando os primeiros senados reinantes e, com eles, as primeiras repúblicas aristocráticas. As potestades paternas converteram-se na nobreza das cidades, e os fâmulos na plebe. Diferente do estágio anterior, nas cidades os nobres se reputavam superiores pela fraude, porque atribuíam a si a descendência dos primeiros deuses das primeiras famílias. O utro argumento que os nobres utilizavam para se proclamarem superiores aos plebeus era o fato de terem a terra por mãe, uma vez que eles haviam sepultado os seus antepassados nos primeiros campos das primeiras semeaduras. Esse costume é explicado com a etimologia da palavra gigante, pois, em latim, ela significa filho da terra, e assim, esses primeiros nobres sustentaram o seu direito heróico sobre os campos com a força das armas e garantiram a propriedade da terra.

A superioridade da nobreza sobre a plebe vigorou durante a idade dos heróis, o segundo período da história universal. A grande diferença entre a idade dos deuses e a idade dos heróis está na complexidade que as religiões adquiriram. Se, na primeira idade do mundo, as religiões eram manifestações espontâneas a ponto de parecerem ordens vindas de uma força superior que os salvaria dos seus males, durante a idade dos heróis, aquelas divindades primitivas receberam novos ornamentos poéticos que não eram tão-só manifestação inconsciente da mente bárbara dos primeiros grupos sociais. As religiões bárbaras, durante da idade dos heróis, já não eram apenas narrativas espontâneas dos fenômenos da natureza, 
tanto os terrestres quanto os celestes. Os nobres utilizavam as religiões para legitimar a dominação social e a suposta superioridade de natureza dos nobres em relação aos plebeus. Por essa razão, as religiões antigas foram também chamadas de falsas e começaram a desaparecer com o surgimento da filosofia.

Em que pese a fraude praticada pelos nobres com as suas religiões, éinquestionável quecom o estabelecimento das republicas aristocráticas e das tiranias surgiram as primei ras formas de governo e, portanto, o nascimento da sociedade civil. $\mathrm{N}$ a idade dos deuses, 0 direito foi divino e era subministrado pelas potestades paternas; na idade dos heróis, o direito era heróico e foi custodiado pelas armas nobres, foi o direito da força. 0 grande traço das sociedades arcaicas é a desigualdade social, primeiro com a distinção entre pais, filhose fâmulos; depois, e com mais violência, entre os nobres e os plebeus.

Somente na idade dos homens é possível a extinção das desigualdades sociais - esta é a grande promessa dos tempos humanos que tem na filosofia a instância de aperfeiçoamento das instituições humanas, cujo ápice é vivido nas repúblicas populares e nas monarquias submetidas às leis civis.

Vico não acreditou na possibilidade da igualdade entre os homens no estado de natureza, pois, segundo ele, é mais sensato admitir que no estado ferino os homens nada entendiam de liberdade e de igual dade de direitos; na barbárie prevaleceu a desigual dade entre os homens. A sociedade humana resulta das singularidades das existências individuais que encontram na vida em sociedade a segurança necessária para a preservação da vida e, ao mesmo tempo, tem no interior da vida social as condições indispensáveis para a celebração da igualdade. A liberdade não existe de forma plena em um estágio de violência ferina, uma vez que nessas circunstâncias não existe igualdade natural, pois há diferenças entre o homem ea mulher, entre 0 adulto e a criança, do mesmo modo que existem pessoas com maior vigor físico e outras mais frágeis. Vico acreditou que a igual dade peculiar à condição humana éa eqüidade civil, pois somente ela écapaz de refletir para fora de cada um a sua verdadeira 
natureza, queéa natureza sociável, ou a exteriorização da sua essência racional, igual em todos os seres, independente do tempo, do lugar, da condição social.

Foi dito no início deste texto que Vico deu importância para os relatos dos viajantes. De fato, e não foi o mero assentimento. Vico percebeu que os povos americanos se encontravam em um estágio cultural similar à barbárie das tribos indo-européias, que estavam registradas nas diversas narrativas míticas da cultura ocidental. Sendo assim, existe nas coisas humanas um padrão moral do comportamento peculiar a cada estágio do desenvolvimento intelectual das sociedades humanas, tanto nos pequenos agrupamentos quanto entre povos inteiros. Vico se referiu a essa constância das coisas humanas utilizando a expressão história ideal eterna: não há a conjunção aditiva que tornaria a expressão relativa a duas ordens históricas: a história ideal e a história eterna. Entenda-se por história ideal eterna o movimento constante da história humana que atravessa o tempo sem se colocar para fora da história e nela busca al cançar o uso pleno da razão, enquanto ideal que nunca é exaurido. Eterna é a condição humana que, independente do tempo e do espaço, se supera com o propósito de atingir a realização plena da sua natureza sociável e racional.

A maneira realista com a qual V ico definiu o curso da história das coisas humanas fez dele um dos poucos filósofos cujo pensamento não foi a expressão do etnocentrismo e do eurocentrismo. Bem distante da mentalidade autoritária doseuropeus colonizadores, V ico sustentou em sua obra que as coisas humanas resultam exclusivamente da vontade e da necessidade dos homens, que, agindo, edificam as suas instituições, os seus valorese os seus conteúdos simbólicos, seja a matemática, seja a filosofia. 0 que podeser extraído da história universal é apenas a constatação da existência de um padrão de comportamento, que foi denominado por Vico de uniformidade de idéias, que atesta a natureza comum dos homens. Não há e não deve haver a pretensão de que a história da cultura européia possa ser o padrão cultural que deve ser imposto a todos os povos, especial- 
mente àqueles povos que se en contram no estágio de desenvolvimento cultural. A esse respeito afirmou que "as coisas fora do seu estado natural não se conservam nem duram" (Sn44, § 134), com isso V ico deixou claro que as ações humanas dependem do livre-arbítrio e não da arbitrariedade dos padrões hegemônicos.

Além da admiração pelos povos ameríndios, a Sn44 expressa também uma severa crítica aos filósofos do Século das Luzes. Vico definiu a tarefa da filosofia com as seguintes palavras: "a filosofia para ajudar o gênero humano deve soerguer e governar o homem caído e débil, sem distorcer-lhe nem abandoná-lo em sua corrupção" (Sn44, § 129). 0 grande problema que acarreta limitações para a aplicação da filosofia nos estudos humanos é que na maioria das vezes, ou quase sempre, as filosofias prescrevem como deve ser 0 homem, sem levar em conta o que o homem é. A compensação para a deficiência das filosofias pode ser encontrada nos estudos que tratam da constituição das leis em conformidade com a natureza dos povos que estão submetidos a elas. Bem antes do surgimento da filosofia, os legisladores já consideravam o homem tal como ele é. Essa constatação torna necessária a nova arte crítica, que foi introduzida com a nova ciência, de maneira que "a filosofia contempla a razão, de on de vem a ciência do verdadeiro; a filologia ${ }^{7}$ observa a autoridade do arbítrio humano, de onde vem a consciência do certo" (Sn44, § 138).

O ra, no tempo da primeira barbárie, ou a barbárie dos sentidos, em que a comunidade humana ain da não era capaz de entender o justo e o sumo bem do ponto de vista universal, foi de grande relevância o reconhecimento do certo das leis, pois elas eram a expressão do senso comum extraído da uniformidade de idéias sobre as necessidades humanas, de modo que esse sen so comum das coisas humanas é "um juízo sem nenhuma reflexão, freqüentemente sentido por toda uma ordem, por todo um povo, por toda uma nação ou por todo o gênero humano" (Sn44, § 142).

O s primeiros códigos de leis surgiram do direito consuetudinário e são, portanto, a expressão das tradições vulgares, que, em 
virtude da passagem dos tempos e "com a mudança das línguas e dos costumes, chegam aténós recobertas de falsidade" (Sn44, § 149). Essa evidência justifica a pertinência da filologia, uma vez que os registros do passado estão recobertos de sedimentos de falsidade colocados pelas sucessivas mudanças sofridas pela língua e pela sua cultura. Assim, a análise filológica, acompanhada da filosofia, torna possível a arqueologia das palavras, a purificação das línguas, e com isso, o resgate da fala original dos povos primitivos, que se serviram dos sinais naturais e das alegorias poéticas para falar de si mesmos, para expressar as suas vontades indefinidas e manifestar as suas crenças muito incertas. Q uando a pesquisa filológica é feita em sintonia com a investigação filosófica, os tempos obscuros são restituídos das suas expressões originais e voltam a comunicar os seus valores morais, em um tempo remoto e sem o auxílio dos filósofos, no qual os homens foram capazes de iniciar o processo civilizador. Por isso, "as falas vulgares devem ser os testemunhos mais graves dos antigos costumes dos povos, que se celebraram no tempo em que eles formaram as línguas" (Sn44, § 151). E, retornando a H omero: "Se os poemas de H omero são histórias civis dos antigos costumes gregos, serão dois grandes tesouros do direito natural das gentes da G récia" (Sn44, § 156).

A investigação sobre o direito natural deve proceder em conformidade com a natureza das coisas humanas; para tanto, a filosofia é indispensável. Porém, é preciso que a análise filosófica seja aplicada sobre os pensamentos humanos, cujos princípios não são de ordens abstratas etranscendentes; pelo contrário, os primeiros pensamentos humanos surgi ram "das necessidades e das utilidades da vida social, que são as duas fontes perenes do direito natural das gentes" (Sn44, § 347). Por isso, a matéria do direito natural começa quando os primeiros homens começaram a pensar humanamente, e não a partir do momento em que "os filósofos começaram a refletir sobre as idéias humanas" (Sn44, §347).

O s primeiros pensamentos nascidos no mundo das gentes continham o germe da racionalidade e da sociabilidade, porém eram 
estruturados por uma lógica poética oposta à lógica formal dos filósofos. Vico se referiu ao comportamento cognitivo dos antigos denominando-o metafísica poética, que éo ponto de partida para o desenvolvimento das ciências e das artes, da mesma forma que essa metafísica é a antítese da filosofia. ${ }^{8}$

0 conhecimento do passado, dentro do propósito da nova ciência, não é a mera enumeração dos feitos do passado. Vico quis fazer uma história das idéias humanas, na qual os feitos do passado são as provas filológicas que são resgatadas para evidenciar 0 desenvolvimento da força racional da humanidade. A história das idéias possibilita o conhecimento da barbárie primitiva, do momento do primeiro pensamento humano, para demonstrar o desenvolvimento desse pensamento na constituição dos primeiros governos humanos, culminando com a filosofia e com o apogeu das nações antigas. Seguiu-se ao apogeu um período de extrema decadência, que para V ico foi a segunda barbárie - ele se referia à vida medieval e aos vínculos vitais entre o homem ea terra. Embora a humanidade tenha conservado as conquistas do período anterior, o comportamento humano recaiu na violência característica da primeira barbárie, surgiu novamente 0 sistema servil, a autoridade ilimitada dos pais de família, o desaparecimento do poder real, o declínio das cidades, enfim, a humanidade adentrou em uma nova barbárie.

0 retorno à barbárie não corresponde a uma repetição histórica; a história das idéias não comporta repetição, os homens criam incessantemente as condições reais de existência, um mesmo evento não se repete. Vico acreditou que o comportamento humano experimenta um novo embrutecimento que acarreta a desigualdade e a opressão social. Porém, a barbárie é o momento no qual a humanidade tem a oportunidade de se colocar, novamente, no processo civilizador; os tempos bárbaros são o prenúncio do recomeço.

Diversos motivos, e aqui cabe destacar apenas o descontentamento de Vico com os rumos da filosofia do seu tempo, reacendiam o temor de uma nova barbárie. 0 fundamento para essa inquietação derivava da refutação quase que completa das disciplinas 
humanistas, tomadas pelo pensamento dos séculos XVII e XVIII como a expressão de uma tradição que sempre se alimentou dos sentidos e das opiniões dos homens; para os modernos a tradição era a grande responsável pela ignorância dos homens. A nova representação do saber, é sabido, tinha a matemática como a expressão da verdade, e a sua aplicação se fazia sobre o mundo natural, pois somente as coisas naturais possuem certeza e exatidão. 0 estudo do homem só é possível, quando ele é tomado como ser natural; essa perspectiva exige o reordenamento da sociedade em conformidade com o modelo abstrato e formal da matemática.

Para Vico, a educação exclusivamente cientificista, da maneira como os seus contemporâneos entendiam a ciência, acarretava 0 distanciamento da pessoa em relação à esfera da vida prática, tornando-a incapaz de trabal hos que dependam da criatividade, pois a nova educação cientificista tolheu o espaço anteriormente destinado à tópica e às demais disciplinas voltadas para o desenvolvimento do engenho humano. A máxima dos modernos no campo educativo era a crítica. Vico não se colocou contrário à filosofia analítica introduzida por D escartes, porém ela deve ser 0 coroamento dos estudos da juventude, edeveter como prérequisito as disciplinas que estimulam a criatividade e possi bilitam o contato das crianças e dos adolescentes com a esfera da vida prática. A máxima educativa de $V$ ico foi primeiro conhecer aquilo que será a matéria da crítica. Cabe registrar que a gnoseologia de Vico desprendia-se da tese do verum-factum, segundo a qual o verdadeiro e o feito se equivalem, logo o conhecer é o fazer, a ação incessante da pessoa humana na história.

A distância entre a educação cientificista e a esfera da vida prática e, mais ainda, da esfera da vida comum em decorrência do solipsismo do cogito, segundo a constatação de Vico, tornava os indivíduos estran hos uns aos outros; desse distanciamento começava a reaparecer aquele comportamento bárbaro que pode causar a ruína da sociedade humana. Diferente da primeira e da segunda barbáries, a terceira, ou a barbárie da reflexão, teria um poder 
destrutivo muito maior, em virtude do progresso acumulado e dos avanços científicos dos primeiros séculos da era moderna. Sobre a barbárie da reflexão, escreveu Vico:

Por tudo isto, com obstinadas facções e desesperadas guerras civis, [os homens] vão fazendo das cidades selvas, e das selvas covis de homens; e de tal maneira, em longos séculos de barbárie, vão arruinar as mal nascidas sutilezas dos engenhos maliciosos, que lhes haviam tornado feras mais imanes com a barbárie da reflexão do que tinha sido na primeira barbárie dos sentidos. $(S n 44, \S 1106)^{9}$

Vico constatou que o progresso contribui para o desenvolvimento vertiginoso das ciências e das artes, porém o mesmo progresso não é percebido nos domínios da moral. ${ }^{10}$ Dessa constatação é extraída uma certeza: não existe uma relação direta entre o rigor matemático e a consciência moral dos homens. A educação moral depende do conhecimento das coisas humanas, mais especificamente do modo como essas coisas se formam e se desenvolvem. 0 direito natural não pode ser conhecido por intermédio da ciência natural, tampouco a moral poderá ser pensada sob o modelo geométrico; o direito natural e a moral dependem da mente humana, cuja formação é anterior ao estabelecimento do formalismo e da abstração das figuras geométricas e dos números. Por isso, ainda no primeiro livro da Sn44, Vico afirmou orgulhoso que a nova ciência era tão exata quanto a geometria e, em contrapartida, muito mais real:

Assim, esta ciência procede justamente como a geometria, que, enquanto constrói os seus elementos os contempla, faz o mundo das grandezas; mas com muito mais realidade quanto mais [reais] são as ordens dos afazeres dos homens, que não são pontos, linhas, superfícies e figuras. ( $(n n 44, \S 349)$

Q uais são os afazeres humanos? É a edificação do sentido humano do mundo com a promoção da justiça social, al go que resulta 
das relações sociais e que não se enquadra no formalismo da razão individualista que acompanhou e prevaleceu depois da descoberta da subjetividade, depois que os modernos, finalmente, constataram que o homem é o criador da sua existência.

ABSTRACT: This paper shows the G. Vico's project of establishment the moral science. Vico was dedicated to emancipating the study of the objective manifestations of the spirit, by means of reforming cartesian rationalism. Illuminism is then criticized by retaking the concept of barbarism, which, in the sphere of philosophy, is opposed to the concept of enlightenment, as understood during the XVIII century.

Key words: G. Vico, rationalism, enlightenment.

\section{Notes}

1. Doravante citada pela abreviatura Sn44, seguida do respectivo parágrafo.

2. A firmação extraída do Livro do A no (1985) daE nciclopédia Barsa, Rio de Janeiro, Encyclopediae Brytanica, 1985.

3. Primeira edição da Scienza nuova, publicada na cidade de $N$ ápoles em 1725.

4. Platão, Íon, 530c. Tradução de Henrique Graciano Muracho, Educação \& Filosofia, n. 10/11, p. 97-114.

5. São as célebres reivindicações de Vico, V ici vindiciae, redigidase enviadas à redação da G azeta Literária de Leipzig em 1729.

6. Hegel, G. W. F. Filosofia da H istória. Brasília: Editora UnB, 1995.

7. Anteriormente, Vico já havia definido a filologia como "a doutrina de todas as coisas que dependem do arbítrio humano, tal como são todas as histórias das línguas, dos costumes e dos feitos, tanto da paz como da guerra entre os povos" (Sn44, § 7).

8. Antítese porque a metafísica poética originou-se da percepção do mundo interior com a sua projeção para o mundo exterior, tal como "o olho corporal que vê todos os objetos fora de si e tem a necessidade do espelho para ver a si mesmo" (Sn44, § 331). 
9. 0 temor de Vico foi confirmado. A dorno e H orkheimer atestam a tese viquiana no livro D ialética do esclarecimento, além do que H orkheimer realizou estudos sobre Vico, tendo dedicado um capítulo da sua tese de habilitação a ele.

10. Essa posição é original em Vico; depois dele, Rousseau e Kant manifestaram-se de maneira parecida a respeito da verdadeira moralidade.

\section{Referêniass}

Croce, B. La filosofia di G. B. Vico. Bari: Laterza, 1980.

PLATÃo, Íon. Tradução de Henrique Graciano M uracho. Educação \& Filosofia, n. 10/ 11, p. 97-114.

Vıco, G. Principi di una scienza nuova (Sn25). In: .0 pere Filosofiche. O rganização de Paolo C ristofolini. Florença: Sansoni Editore, 1971. p. 169-337.

. Vici Vindiciae (V ici V ind., 1729). In: . 0 pere Filosofiche. O rganização de Paolo C ristofolini. Florença: Sansoni Editore, 1971. p. 339-375.

. Princìi di scienza nuova (Sn44). O rganização de Fausto Nicolini. Milão: Arnoldo Mondadori, 1992. 